\title{
Antibacterial Activity of a Novel Depsipeptide and Prodigiosine of Serratia marcescans S823
}

\author{
Linyan Zhu ${ }^{1}$, Cuiping Pang ${ }^{2}$, Liqun Chen ${ }^{1}$ and Xiangdong Zhu ${ }^{3^{*}}$ \\ ${ }^{1}$ College of Bioscience and Bioengineering, Fuzhou University, Fuzhou, 350116, China \\ ${ }^{2}$ College of Bioengineering, Jiangnan University, Wuxi, 214122, China \\ ${ }^{3}$ College of Bioscience and Bioengineering, Jiangxi Agricultural University, Nanchang, 330045, China
}

"Corresponding author: Xiangdong Zhu, College of Bioscience and Bioengineering, Jiangxi Agricultural University, Nanchang, 330045, China, Tel: +08615979170780; E-mail: zhuxdau@qq.com

Received: January 05, 2018; Accepted: January 17, 2018; Published: January 25, 2018

Copyright: @ 2018 Zhu L, et al. This is an open-access article distributed under the terms of the Creative Commons Attribution License, which permits unrestricted use, distribution, and reproduction in any medium, provided the original author and source are credited.

\begin{abstract}
To investigate the antimicrobial activity of secondary metabolites from Serratia marcescans S823. The strain Serratia marcescans S823 was screened for its antibacterial activity. The active components from the bacterium were isolated by bioactivity-guided analysis. Their structures were identified by chemical and spectroscopic methods to be prodigiosine (PG) (1), serratamolide A (2) and serratamolide $G(3)$, which is a new compound. The MIC and MBC of prodigiosine and serratamolide $G$ were $6.25 \mu \mathrm{g} \cdot \mathrm{mL}^{-1}$ and $12.5 \mu \mathrm{g} \cdot \mathrm{mL}^{-1}$ against $C$. albicans and $6.25 \mu \mathrm{g} \cdot \mathrm{mL}^{-1}$ and $25 \mu \mathrm{g} \cdot \mathrm{mL}^{-1}$ against $B$. thuringiensis respectively. They might be potential alternative treatment options for Candida albicans infection. This study encourages further investigation of natural products as new antibiotics.
\end{abstract}

Keywords: Antibiotics; Prodigiosine; Serratamolide G; Serratia marcescans

\section{Introduction}

Precursor compounds from natural resources represent a promising source of active antimicrobial components. Microbial resources are very rich and have great potential to be exploited. Some scholars have isolated prodigionines, such as prodigiosine (PG) and Undecylprodigiosin (UP) with a linear alkyl group chain, metacycloprodionine (MP), cycloprodigiosine (CPrG), marineosin A and marineosin B with a ring alkyl group chain [1,2], from Serratia and Streptomyces. These compounds contain a large conjugate system skeleton of a three-pyrrole ring. The A and B pyrrole rings are directly connected, while the third ring is connected by a methyl bridge $[3,4]$. These components are synthesized by Gram-positive bacteria and Gram-negative bacteria, such as Pseudomonas, Vibrio, Streptomyces and Serratia, that have antimicrobial activity [5], anti-malarial activity [6,7], immunosuppressive activity [8-10], and antitumor activity [11-13]. Serratamolide was isolated for the first time in 1961 [14] from a Serratia marcescens. This cyclic tetradepsipeptide contains two units of (R)- $\beta$-hydroxydecanoic acid and two units of L-serine, in alternate positions, which is a metabolic product of this bacterium. In the first studies performed, this compound showed activity against a number of bacteria, yeasts and pathogenic fungi [15]. Therefore, secondary products have a broad prospective medicinal value.

In this investigation, we used cholesterol as the sole carbon source to screen microbial transformation strains and obtained microorganisms with specific transformation functions that can convert cholesterol into 7-hydroxycholesterol [16]. The strains screened were identified and found to be Serratia via colony morphology observations, biochemical experiments and 16S rDNA sequence analysis. Their antibacterial activity aroused our interest. These strains were further screened to assess their antibacterial activity.
We found that the extract of Serratia marcescans S823 had antibacterial activity. On this basis, the secondary metabolites produced by this bacterium were studied, and three compounds were isolated from bacteria by tracing their antibacterial activity. They were identified using chemical and spectroscopic methods to be prodigiosine (PG) (1), serratamolide A (2) and serratamolide G (3) as a novel compound. The antibacterial activity of the three compounds were studied. The two compounds, prodigiosine (PG), serratamolide G had almost the same antibacterial activities against Candida albicans and Bacillus thuringiensis as the standard antibiotic penicillin.

\section{Materials and Methods}

\section{Microorganisms, media and culture conditions}

All reagents were purchased from Sinopharm Chemical Reagent Co., Ltd. Serratia marcescans S823 used for antibiotic production was stored in the key microorganisms laboratory of Nanchang, at the College of Bioscience and Bioengineering of the Jiangxi Agricultural University (Nanchang, China). The strain was inoculated in a $250 \mathrm{ml}$ Erlenmeyer flask containing $100 \mathrm{ml}$ of fermentation medium (yeast extract, $5 \mathrm{~g} ; \mathrm{K}_{2} \mathrm{HPO}_{4}, 0.25 \mathrm{~g} ; \mathrm{MgSO}_{4}, 0.25 \mathrm{~g} ; \mathrm{MnSO}_{4} \cdot \mathrm{H}_{2} \mathrm{O}, 0.01 \mathrm{~g}$; $\mathrm{FeSO}_{4} .7 \mathrm{H}_{2} \mathrm{O}, 0.001 \mathrm{~g} ; \mathrm{NaCl}, 0.5 \mathrm{~g} ; \mathrm{CaCl}_{2}, 0.001 \mathrm{~g}$; and distilled water, $1000 \mathrm{ml}, \mathrm{pH} 7.0-7.2)$ at $28-30^{\circ} \mathrm{C}$ on a rotary shaker at $180 \mathrm{rpm}$ for $48 \mathrm{~h}$. After the fermentation liquid was removed by centrifugation at 10000 rpm for $10 \mathrm{~min}$, the bacteria were leached with acetone using an ultrasonic method for $20 \mathrm{~min}, 3$ times. Then, the liquid was filtered and condensed by vacuum rotary evaporation at $50^{\circ} \mathrm{C}$ to isolate compounds with antibacterial activity.

\section{Antimicrobial activity assays}

The microorganisms Candida albicans, Escherichia coli, Bacillus subtilis, Staphylococcus aureus and Bacillus thuringiensis used in this experiment were obtained from the key microorganisms laboratory of 
Nanchang, College of Bioscience and Bioengineering, Jiangxi Agricultural University (Nanchang, China). The antibacterial activity of organic extracts of Serratia marcescans S823 and its compounds was determined using the agar diffusion assay. Twenty millilitres of sterile nutrient agar medium was poured into sterile petri dishes and allowed to solidify. The petri dishes were incubated at $37^{\circ} \mathrm{C}$ for $24 \mathrm{~h}$. The medium was then seeded with organisms by the pour plate method using sterile top agar $(4 \mathrm{ml})$ containing $1 \mathrm{ml}$ of culture. These cultures were first adjusted to a concentration of $10^{6} \mathrm{cfu} \mathrm{ml}^{-1}$. After solidification of the medium, cups with a diameter of $7 \mathrm{~mm}$ were placed on the solidified agar at an equal distance from one another. The dried extract of Serratia marcescans S823 and other compounds was dissolved in methyl alcohol to obtain a concentration of 200 $\mu \mathrm{g} . \mathrm{mL}^{-1}$. Then these solution were filtered through a filter membrane. One-hundred microliter solutions of the extract or compounds were added to their respective cups. One-hundred microliters of penicillin at a concentration of $200 \mu \mathrm{g} \cdot \mathrm{mL}^{-1}$ was used as the standard reference against the bacteria. The petri dishes were kept in the refrigerator at $4^{\circ}$ $\mathrm{C}$ for $0.5 \mathrm{~h}$ for diffusion. After diffusion, the petri dishes were incubated at $37^{\circ} \mathrm{C}$ for $24 \mathrm{~h}$ and the inhibition zones were observed and measured. An equivalent amount of methyl alcohol was used as the negative control. The diameter of the bacteriostatic ring $(\mathrm{mm})$ indicated antibacterial activity changes. Each experiment was repeated three times.

Minimum inhibitory concentration (MIC) and minimum bactericidal concentration (MBC) were measured based on the agar diffusion assay and the microdilution method. For MIC determination of the purified compounds serial 2-fold dilutions of each compound, namely, 200, 100, 50, 25, 12.5, 6.25 and $3.125 \mu \mathrm{g} \cdot \mathrm{mL}^{-1}$ were performed in their respective cups. Penicillin was used as the standard antibiotic at a concentration of $200 \mu \mathrm{g} . \mathrm{mL}^{-1}$. In each 96 -well microplate, $100 \mu \mathrm{L}$ of nutrient broth, $10 \mu \mathrm{L}$ of the standardized bacterial suspension and $20 \mu \mathrm{L}$ of the mother solution of compounds were distributed (200-3.125 $\left.\mu \mathrm{g} . \mathrm{mL}^{-1}\right)$ and the plates were incubated at $37^{\circ} \mathrm{C}$ for $24 \mathrm{~h}$. Ten microlitres of the revealing substance $\left(5 \mathrm{mg} \mathrm{ml}^{-1} \mathrm{MTT}\right)$ were then added, followed by incubation for an additional $4 \mathrm{~h}$ and centrifuged under $1500 \mathrm{~g}$ for $20 \mathrm{~min}$. The supernatant was removed. Then $150 \mu \mathrm{L}$ of dimethyl sulfoxide (DMSO) was added in wells. The plate was oscillated for $30 \mathrm{~min}$. All tests were carried out in triplicate. The plate was then examined considering the last well in which no growth was visible (non-blue coloration) as the MIC.

The MBC was determined from the plate containing Potato dextrose broth agar from the last well without growth to the well with the greatest concentration.

The plant pathogenic fungi, including Fusarium oxysporum f. sp. niveum, Verticillium dahliae Kleb, Botryosphaeria dothidea and Fusarium oxysporum f. sp. vasinfectum, used in this experiment were obtained from Microbiology Key Laboratory of Nanchang, Jiangxi Agricultural University. The antifungal activity of organic extracts of Serratia marcescans S823 and its compounds was measured using the mycelium growth rate method to inhibit fungi of different plant pathogens. In this experiment, a double-layer plate method was used. The lower layer of the plate $(\Phi 90 \mathrm{~mm})$ contained $12 \mathrm{~mL}$ of PDA medium, and the upper layer was a mixture of $10 \mathrm{ml}$ of PDA medium and $2 \mathrm{ml}$ of bacteria extract. Ten millilitres of medium mixed with $2 \mathrm{ml}$ of methanol was used as the negative control, and $10 \mathrm{ml}$ of medium mixed with $2 \mathrm{ml}$ of validamycin at a concentration of $100 \mu \mathrm{g} \cdot \mathrm{mL}^{-1}$ was used against the fungi as the positive control. After medium solidification under aseptic operation conditions, the perforating device $(\Phi 8 \mathrm{~mm})$ was used to make a good test pathogenic fungus block and transfer the fungal block to the centre of each treatment plate. The temperature was held constant at $28^{\circ} \mathrm{C}$, and the experiment was repeated three times. The colony diameter of each group was measured and recorded by the crossing method when the control group colony covered approximately two-thirds of the petri dishes after 4 days.

Fractions from the chromatographic column were detected by thin layer chromatography (TLC) and spread in a chloroform-methyl alcohol system $(15: 1, \mathrm{v} / \mathrm{v})$. The spots were sprayed with a $50 \%$ sulfuric acid ethanol solution.

\section{Isolation of compounds}

The obtained concentrate was dissolved using chloroform and mixed with silica gel. It was subsequently submitted to column chromatography (column: $2 \times 40 \mathrm{~cm}$ ), using silica gel (Qingdao Haiyang Chemical Co., Ltd, Shandong, China) as the adsorbent. Elution was performed using gradient mixtures of chloroformmethanol (100:0-70:30, v/v). Then, according to the TLC test results, the same flow of eluate was combined. The obtained fractions were tested by an antimicrobial activity assay, such as by observing the inhibition zones against Bacillus thuringiensis and Candida albicans. An activity fraction was submitted to RP-C18 (Merck, Germany) column chromatography using gradient mixtures of water and methanol (70:30-0:100, v/v) as the eluate. Each eluate flow was tested by an antimicrobial activities assay. Then, the obtained fraction was successively subjected to column chromatography on Sephadex LH20 (Pharmacia, NJ, USA) using the chloroform-methanol system (1:1, $\mathrm{v} / \mathrm{v})$. According to the antimicrobial activity assay as well as the TLC test, the activities of the compounds were then determined.

\section{Morphological characteristics and identi ication of the Serratia marcescans $\mathbf{5 8 2 3}$}

The morphological characteristics of the Serratia marcescans S823 isolate were observed using a scanning electron microscope (Hitachi, Japan). Identification of Serratia marcescans S823 was performed by $16 \mathrm{~S}$ rDNA gene sequencing and phylogenetic analysis. Total genomic DNA was extracted using the SK8259 Ezup pillar bacterial genomic DNA extraction kit (Sangon Biotech, Shanghai, China). 16S rDNA was amplified by the primer A(5'-CAGAGTTTGATCCTGGCT-3') and primer B (5'-AGGAGGTGATCCAGCCCA-3'). Samples were amplified using the following program: $94^{\circ} \mathrm{C}$ for $5 \mathrm{~min}$, followed by 5 cycles of denaturation at $94^{\circ} \mathrm{C}$ for $30 \mathrm{~s}$, with annealing at $55^{\circ} \mathrm{C}$ for $35 \mathrm{~s}$, extension at $72^{\circ} \mathrm{C}$ for $1 \mathrm{~min}$ and 35 cycles of extension for $8 \mathrm{~min}$. PCR products were assayed by $1 \%$ agarose gel electrophoresis. The target bands were cut out of the gel and the electrophoresis product was purified using the UNIQ-10 column DNA gel recovery kit. The DNA was subsequently sequenced by Sangon Biotech Co. Ltd. (Shanghai, China). The obtained $16 \mathrm{~S}$ rDNA sequence was analysed using BLAST algorithms from the National Center for Biotechnology Information website (http://www.ncbi.nlm.nih.gov /BLAST). A phylogenetic tree was constructed using the Neighbour-Joining method of the MEGA 6.06 software, and the evolutionary distance was calculated using the Distance Kimura2-Parameter model. The confidence of the phylogenetic tree was evaluated according to the bootstrap value (with the bootstrap repeated 1000 times). 


\section{Identification of products}

The compounds in the fractions were analysed using nuclear magnetic resonance spectrometry (Bruker, Karlsruhe, Germany) at a $600 \mathrm{~Hz}$ frequency, deuterated chloroform as the solvent, and TMS as the internal standard. ESI-MS and HR-ESI-MS were measured on a mass spectrometer (Agilent, Palo Alto, USA) using methanol as the solvent and ESI $(+)$ and ESI (-) for ionization. Optical rotations were obtained on a Horiba SEPA-300 polarimeter.

\section{Results}

\section{Characterization and identification of Serratia marcescans S823}

The morphological characteristics of Serratia marcescans S823 were visualized using a scanning electron microscope. It was found to be a peritrichous Gram-negative bacteria, with a size of (1-1.3) $\mu \mathrm{m} \times$ $(0.7-1.0) \mu \mathrm{m}$. It had no capsule and did not form spores. Its colonies were bulging, round and smooth, and moist, with opaque centres, neat edges, and a dark red colour. They were easy to pick when cultured at $30^{\circ} \mathrm{C}$ on a plate for $36 \mathrm{~h}$. When the culturing time was over $72 \mathrm{~h}$, the colonies were easily dendritic, with irregular edges. They were turbid and had bacterial membranes in liquid medium. The colony on the screening plate was pink and opaque. A micrograph of the strain is shown in Figure 1.

A phylogenetic tree of strain S823 was constructed using the $16 \mathrm{~S}$ rDNA gene sequence (1434 bp). This sequence was submitted to GenBank with the accession number KR817904.1 to obtain 16S rRNA sequences from 12 standard strains of Serratia from GenBank for phylogenetic analysis. Figure 2 shows phylogenetic trees that were constructed based on the similarity of the 16S rRNA sequences. Strain S823 has high homology with Serratia and 99\% homology with Serratia marcescans. Combined with the previous morphological observations, bacterial S823 strain was identified as Serratia marcescans $\mathrm{S} 823$.

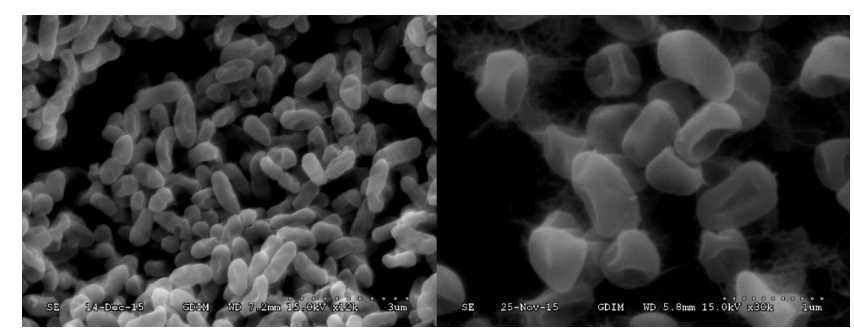

Figure 1: Scanning electron micrograph of Serratia marcescans S823.

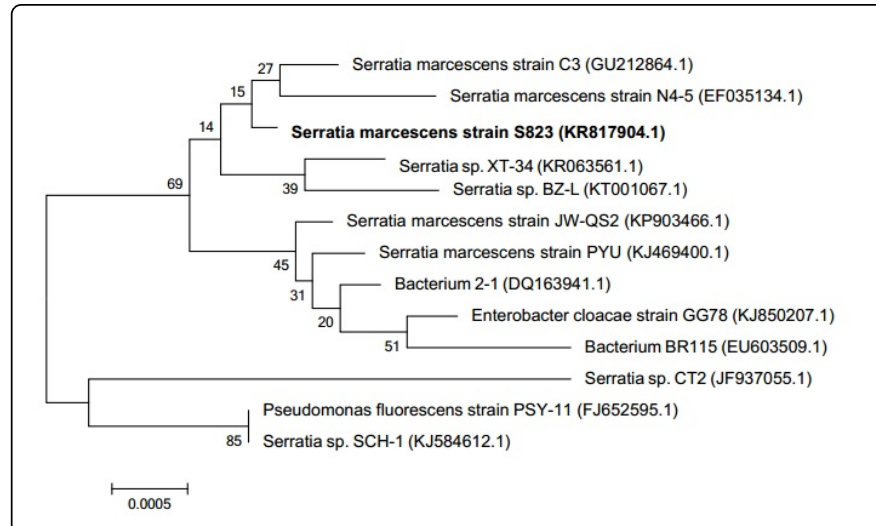

Figure 2: Phylogenetic tree of strain S823 based on the $16 \mathrm{~S}$ rDNA gene sequence.

\section{Isolation of compounds by bioactivity-guided analysis}

Strain $\mathrm{S} 823$ was inoculated at $28-30^{\circ} \mathrm{C}$ on a rotary shaker at $180 \mathrm{rpm}$ for $48 \mathrm{~h}$. After a total volume of 1 litres of fermentation liquid was removed by centrifugation at $10000 \mathrm{rpm}$ for $10 \mathrm{~min}$, the bacterial body was extracted with acetone via the ultrasonic method for $20 \mathrm{~min}, 3$ times. The bacteria were filtered and then condensed by vacuum rotating evaporation at $50^{\circ} \mathrm{C}$, and $3.26 \mathrm{~g}$ of concentrate was obtained. The obtained concentrate was dissolved using methyl alcohol and was mixed with silica gel. It was subsequently submitted to column chromatography using silica gel as the adsorbent. Elution was performed using gradient mixtures of chloroform-methanol $(100: 0-70: 30, v / v)$, and 22 flows of eluate were obtained, with each fraction being $80 \mathrm{~mL}$. Then, according to the TLC test results, the same flows of eluate were combined with each other and Fr1 to Fr7 were harvested. Fr1 to Fr7 were tested by an antimicrobial activity assay, such as the inhibition zones against Bacillus thuringiensis and Candida albicans. Fr3 showed an inhibitory effect against Bacillus thuringiensis and Candida albicans. TLC showed that Fr3 had only one red spot. This suggested that Fr3 was a pure compound. The weight of Fr3 was 62 mg. Fr1-Fr2 and Fr5-Fr7 showed no inhibition zones against Bacillus thuringiensis and Candida albicans, while Fr4 had inhibition zones against Bacillus thuringiensis and Candida albicans. Fr4 was submitted to RP-C18 column chromatography using gradient mixtures of water methanol (70:30-0:100, v/v) as the eluate. Nine eluate flows were harvested, and each fraction was $60 \mathrm{ml}$. Each flow of eluate was also tested by an antimicrobial activity assay. Fr4.1-Fr4.4 and Fr4.8Fr4.9 showed also no inhibition zones against Bacillus thuringiensis and Candida albicans, while Fr4.5-Fr4.7 had inhibition zones against them. TLC showed that Fr4.5-Fr4.7 had two main spots $\left(\mathrm{R}_{\mathrm{f}} 0.46\right.$ and $0.37)$. Then, they were combined, weighed $(0.93 \mathrm{~g})$, and the fractions were successively subjected to column chromatography on Sephadex LH20 using the chloroform-methanol system $(1: 1, \mathrm{v} / \mathrm{v})$. Ten flows of eluate were harvested, and each fraction was $5 \mathrm{~mL}$. The TLC test showed that fraction numbers $2-4$ had the same spots, which were combined $\left(\mathrm{R}_{\mathrm{f}} 0.46\right)$, namely compound 3 , while fraction numbers $7-8$ had the same spots, which were combined $\left(\mathrm{R}_{\mathrm{f}} 0.37\right)$ (Figure 3 ), namely compound 2. According to the antimicrobial assay, compound 3 was the active compound. 


\section{Structural identification of the products}

Compound 1: Compound 1 was characterized by ESI-MS and ${ }^{1} \mathrm{H}-$ $\mathrm{NMR}$ and ${ }^{13} \mathrm{C}$-NMR. The maximum UV absorbance was observed at $535 \mathrm{~nm}$. The ${ }^{13} \mathrm{C}$ spectrum revealed 20 carbon signals. ESI-MS data showed ion peaks $\left[\mathrm{M}^{+} \mathrm{H}\right]^{+} \mathrm{m} / \mathrm{z}$ at 324.3, which agreed with the formula $\mathrm{C}_{20} \mathrm{H}_{25} \mathrm{~N}_{30}$. The ${ }^{1} \mathrm{H}$ NMR data were summarized as ${ }^{1} \mathrm{H}$ NMR $\left(\mathrm{CD}_{3} \mathrm{Cl}\right.$, $600 \mathrm{MHz}): \delta_{\mathrm{H}} 12.55\left(\mathrm{~m}, \mathrm{NH}_{1}\right), 12.70\left(\mathrm{~m}, \mathrm{NH}_{6}\right), 7.22(\mathrm{~s}, 1 \mathrm{H}, \mathrm{H}-2), 6.35$ $(\mathrm{t}, \mathrm{J}=1.8 \mathrm{~Hz}, 1 \mathrm{H}, \mathrm{H}-3), 6.91(\mathrm{~m}, 1 \mathrm{H}, \mathrm{H}-4), 6.08(\mathrm{~d}, \mathrm{~J}=1.8 \mathrm{~Hz}, 1 \mathrm{H}, \mathrm{H}-8)$, $6.94(\mathrm{~m}, 1 \mathrm{H}, \mathrm{H}-12), 6.67(\mathrm{~s}, 1 \mathrm{H}, \mathrm{H}-14), 4.00(\mathrm{~s}, 3 \mathrm{H}, \mathrm{O}-\mathrm{Me}), 2.38(\mathrm{t}$, 2H,H-18), 2.54 (s, 3H,H-15), 1.2-1.4 (m, 6H.H-19-21), and 0.89 (t, 3H, $\mathrm{H}-22)$. The ${ }^{13} \mathrm{C}-\mathrm{NMR}$ data were summarized as ${ }^{13} \mathrm{C}-\mathrm{NMR}\left(\mathrm{CD}_{3} \mathrm{Cl}, 150\right.$ MHz): $\delta_{\mathrm{C}} 126.9(\mathrm{C}-2), 111.7(\mathrm{C}-3), 117.0(\mathrm{C}-4), 122.2(\mathrm{C}-5), 147.7(\mathrm{C}-7)$, 92.8(C-8), 165.5(C-9), 120.7(C-10), 58.7(C-1),116.0(C-12), 125.1(C-13), $128.5(\mathrm{C}-14), \quad 128.5(\mathrm{C}-15), \quad 147.0(\mathrm{C}-16), \quad 12.4(\mathrm{C}-17)$, 25.3(C-18), 29.8(C-19), 30.6(C-20), 22.5(C-21), and 14.1(C-22), which confirmed the structure of prodigiosin (5[(3-methoxy-5pyrrol-2-ylidene-pyrrol -2-ylidene) -methyl]-2-methyl- 3-pentyl-1 $\mathrm{H}$ pyrrole) [17] see Figure 4.

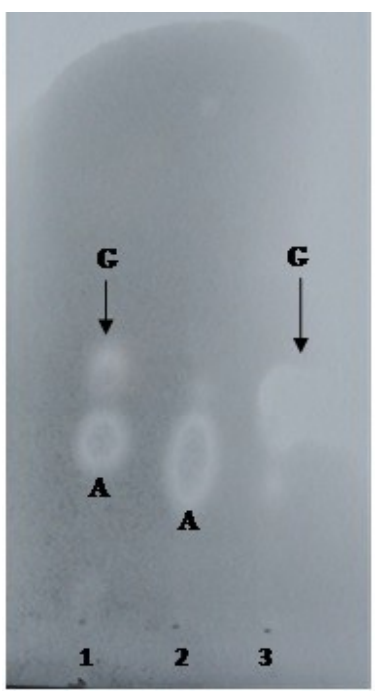

Figure 3: The TLC of serratamolide A and serratamolide G. A, serratamolide A; G, serratamolide G. Compounds. Compounds were spread in a chloroform-methyl alcohol system (15:1, v/v). The spots were sprayed with a $50 \%$ sulfuric acid ethanol solution.

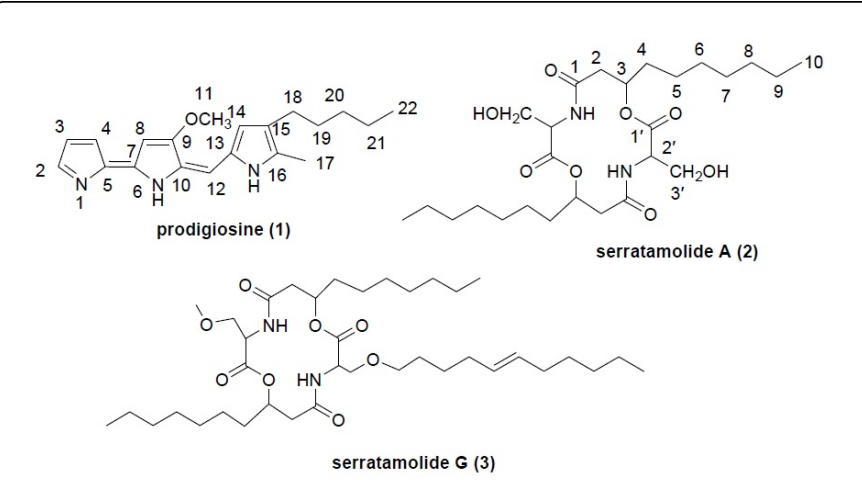

Figure 4: The structure of the products.

Compound 2: The structure of compound 2 was readily elucidated from the combined NMR and ESI-MS data. The ESI-MS data showed ion peaks $\left[\mathrm{M}^{-} \mathrm{H}\right]^{-}$at $\mathrm{m} / \mathrm{z} 513.3$ and $\left[\mathrm{M}^{+} \mathrm{H}\right]^{+}$at $\mathrm{m} / \mathrm{z}$ 515.3. The ${ }^{13} \mathrm{C}$ NMR spectrum showed only 13 signals, which comprised two carbonyl signals at $\delta_{\mathrm{C}} 169.6$ and 169.5 , one methyl, eight methylene, and two methine carbons from the DEPT-135 spectrum. The ${ }^{1} \mathrm{HNMR}$ spectrum of compound 2 (Table 1) showed a simple set of signals, from which the HSQC spectrum consisted of a serine and $\beta$-hydroxy fatty acid moiety that could be readily correlated with the two moieties found in the ${ }^{13} \mathrm{C}$ NMR spectrum (Table 1). The ESI-MS data were compatible with the molecular formula of $\mathrm{C}_{26} \mathrm{H}_{46} \mathrm{~N}_{2} \mathrm{O}_{8}$. The ESI-MS and ${ }^{13} \mathrm{C}$ NMR data were only compatible with a symmetrical molecule. The ${ }^{1} \mathrm{H}$ NMR spectrum indicated that a C-10 $\beta$-hydroxy fatty acid moiety was attached to the serine unit through its hydroxy group from the low-field shift of $\mathrm{H}-3$ and the three-bond HMBC correlation of this proton with the C-1' of serine in the HMBC. According to the degree of unsaturation, the cyclic nature of the molecule was necessary based on the molecular weight and symmetry, which was confirmed by the observation of a strong three-bond correlation of C-1 with $\mathrm{H}-2$ '. A literature search indicated this product had been isolated previously from various strains of S.marcescens [18] and chemically and spectroscopically characterized as serratamolide A (2), a 14-membered cyclic depsipeptide incorporating L-serine and D-3-hydroxy-C10:0 acid [19] (see Figure 4).

\begin{tabular}{|c|c|c|c|c|c|c|c|c|c|c|c|c|c|c|c|c|c|}
\hline \multirow{2}{*}{\multicolumn{6}{|c|}{$\begin{array}{l}\text { Serratamolide A (2) } \\
\mathrm{J} \text { in } \mathrm{Hz}\end{array}$}} & \multicolumn{12}{|c|}{ Serratamolide G (3) } \\
\hline & & & & & & \multicolumn{4}{|c|}{$\mathrm{C}_{10}$ alkyl chain } & \multicolumn{8}{|c|}{$\mathrm{C}_{10}$ alkyl chain and $\mathrm{C}_{11: 1}$ alkyl chain } \\
\hline No. & $\delta_{\mathrm{H}}$ & m & & $\delta_{C}$ & & no. & $\delta_{\mathrm{H}}$ & $\mathbf{m}$ & $\mathrm{J}$ in $\mathrm{Hz}$ & $\delta_{C}$ & m & no. & $\delta_{\mathrm{H}}$ & $\mathbf{m}$ & $\mathrm{J}$ in $\mathrm{Hz}$ & $\delta_{C}$ & m \\
\hline 1 & - & - & - & 169.6 & $\mathrm{~s}$ & 1 & - & - & - & 172.7 & $\mathrm{~s}$ & 1" & & & & 170.1 & s \\
\hline 2 & A2.62 & dd & $13.8,4.8$ & 40.4 & $\mathrm{t}$ & 2 & A2.61 & dd & $13.6,4.8$ & 41.1 & $\mathrm{t}$ & $2 "$ & A2.46 & dd & $13.6,4.8$ & 42.9 & $t$ \\
\hline & B2.42 & dd & $13.8,3.0$ & - & - & - & B2.45 & dd & $13.6,2.9$ & & & & B2.44 & $\mathrm{dd}$ & $13.6,2.9$ & & \\
\hline 3 & 5.31 & $\mathrm{~m}$ & & 72.4 & d & 3 & 5.28 & $\mathrm{~m}$ & & 73.2 & d & $3 "$ & 4.02 & $\mathrm{~m}$ & & 68.9 & d \\
\hline 4 & 1.72 & $\mathrm{~m}$ & & 32.4 & $\mathrm{t}$ & 4 & A1.7 & $\mathrm{m}$ & & 33.8 & $\mathrm{t}$ & $4 "$ & A1.68 & & & 31.8 & $\mathrm{t}$ \\
\hline
\end{tabular}




\begin{tabular}{|c|c|c|c|c|c|c|c|c|c|c|c|c|c|c|c|c|c|}
\hline & & & & & & & B1.65 & $\mathrm{m}$ & & & & & B1.65 & $\mathrm{m}$ & & & \\
\hline 5 & 1.32 & $\mathrm{~m}$ & & 25.8 & $\mathrm{t}$ & 5 & 1.29 & $\mathrm{~m}$ & & 25.6 & $\mathrm{t}$ & $5^{\prime \prime}$ & 1.29 & & & 25.3 & $t$ \\
\hline 6 & 1.32 & $\mathrm{~m}$ & & 29.2 & $t$ & 6 & 1.29 & $\mathrm{~m}$ & & 29.2 & & 6" & 1.29 & & & 29.2 & $\mathrm{t}$ \\
\hline 7 & 1.32 & $\mathrm{~m}$ & & 29.2 & $\mathrm{t}$ & 7 & 1.29 & $\mathrm{~m}$ & & 29.3 & & 7" & 1.29 & $\mathrm{~m}$ & & 29.3 & $t$ \\
\hline 8 & 1.32 & $\mathrm{~m}$ & & 31.8 & $\mathrm{t}$ & 8 & 1.29 & $\mathrm{~m}$ & & 29.2 & $\mathrm{t}$ & 8" & 1.29 & $\mathrm{~m}$ & & 29.2 & $t$ \\
\hline 9 & 1.32 & $\mathrm{~m}$ & & 22.6 & $t$ & 9 & 1.29 & $\mathrm{~m}$ & & 22.7 & $t$ & 9" & 1.29 & $\mathrm{~m}$ & & 22.7 & $t$ \\
\hline 10 & 0.87 & $\mathrm{t}$ & 6.7 & 14.1 & $q$ & 10 & 0.88 & t & 6.6 & 14.1 & $\mathrm{t}$ & $10^{\prime \prime}$ & 0.88 & $t$ & 6.6 & 0.87 & $q$ \\
\hline $1^{\prime}$ & & & & 169.5 & $\mathrm{~s}$ & $1^{\prime}$ & & & & 171.5 & $\mathrm{~s}$ & $1^{\prime \prime \prime}$ & & & & 171.0 & $\mathrm{~s}$ \\
\hline $2^{\prime}$ & 4.65 & dd & $2.4,3.0$ & 56.3 & d & $2^{\prime}$ & 4.66 & $\mathrm{~m}$ & & 55.1 & $d$ & $2^{\prime \prime \prime}$ & 4.63 & $\mathrm{~m}$ & & 54.7 & d \\
\hline \multirow[t]{14}{*}{$3^{\prime}$} & A4.23 & dd & $10.8,2,4$ & 63.2 & $\mathrm{t}$ & $3^{\prime}$ & A4.01 & dd & $10.8,3.9$ & 63.2 & $\mathrm{t}$ & $3^{\prime \prime \prime}$ & A3.89 & $\mathrm{m}$ & & 63.1 & $\mathrm{t}$ \\
\hline & B3.86 & dd & $10.8,3.0$ & & & & B4.01 & dd & $10.8,3.4$ & & & & B3.87 & $\mathrm{m}$ & & & \\
\hline & & & & & & $\mathrm{OCH}_{3}$ & 3.79 & $\mathrm{~s}$ & & & & $1^{\prime \prime \prime \prime}$ & A3.98 & $\mathrm{m}$ & & 62.5 & $t$ \\
\hline & & & & & & & & & & & & & B3.78 & $\mathrm{m}$ & & & \\
\hline & & & & & & & & & & & & $2^{\prime \prime \prime \prime}$ & 1.63 & $\mathrm{~m}$ & & 31.7 & $\mathrm{t}$ \\
\hline & & & & & & & & & & & & $3^{\prime \prime \prime \prime}$ & 1.53 & $\mathrm{~m}$ & & 37.1 & $t$ \\
\hline & & & & & & & & & & & & $4^{\prime \prime \prime \prime}$ & 1.71 & $\mathrm{~m}$ & & 31.8 & $t$ \\
\hline & & & & & & & & & & & & $5^{\prime \prime \prime \prime}$ & 5.56 & $\mathrm{~m}$ & & 124.0 & d \\
\hline & & & & & & & & & & & & $6^{\prime \prime \prime \prime}$ & 5.38 & $\mathrm{~m}$ & & 133.8 & $d$ \\
\hline & & & & & & & & & & & & $7^{\prime \prime \prime \prime \prime}$ & 2.02 & $\mathrm{~m}$ & & 27.5 & $t$ \\
\hline & & & & & & & & & & & & $8^{\prime \prime \prime \prime}$ & 1.46 & $\mathrm{~m}$ & & 37.1 & $t$ \\
\hline & & & & & & & & & & & & $9^{\prime \prime \prime \prime}$ & 1.29 & $\mathrm{~m}$ & & 29.0 & $t$ \\
\hline & & & & & & & & & & & & $10^{\prime \prime \prime \prime}$ & 1.25 & $\mathrm{~m}$ & & 29.1 & $t$ \\
\hline & & & & & & & & & & & & $11^{\prime \prime \prime \prime}$ & 0.87 & $t$ & & 14.1 & $q$ \\
\hline
\end{tabular}

Table 1: NMR Data for Serratamolides A (2) and G(3) in $\mathrm{CDCl}_{3}$.

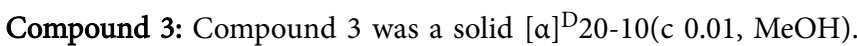
Its ${ }^{13} \mathrm{C}$ NMR spectrum showed 35 signals, from which the DEPT-135 spectrum was composed of four carbonyl signals at $\delta 172.7,171.5170 .0$ and 169.7. There were twenty-four methylene and six methine carbons, two of which were sp2 hybridized at $\delta 133.8$ and 124.0. Integration of the ${ }^{1} \mathrm{H}$ NMR spectrum and ${ }^{13} \mathrm{C}$ NMR indicated that the compound had three methyl groups and one methoxyl group. This suggested that the compound had 37 carbons. Both the ${ }^{1} \mathrm{H}$ and ${ }^{13} \mathrm{C}$ NMR spectra of compound 3 indicated that this compound was related to 2, but had another branch chain and was unsymmetrical. The HRESI-MS data showed ion peaks $\left[\mathrm{M}^{-} \mathrm{H}\right]^{-}$at $\mathrm{m} / \mathrm{z} 665.3976$, which confirmed that the molecular formula was $\mathrm{C}_{37} \mathrm{H}_{64} \mathrm{~N}_{2} \mathrm{O}_{8}$. The ${ }^{1} \mathrm{H}$ and ${ }^{13} \mathrm{C}$ NMR spectra of it indicated the presence of an unsaturated $\mathrm{C} 11: 1$ unit except for the same part as 2. Two $\mathrm{H}$ multiplets between $\delta_{\mathrm{H}} 5.28$ and 4.02 were characteristic of the H-3 found in 3, which had crosses at $\delta_{c} 73.2$ and 68.9 in the HSQC spectrum. One double bond at $\delta_{\mathrm{H}} 5.56$ and 5.38, which had crosses at $\delta_{\mathrm{c}} 133.8$ and 124.0 in the HSQC spectrum, was found in the third branch chain unit. The presence of the double bond was determined from the HMBC and $\mathrm{H}-\mathrm{H}$ COSY spectra. It was a new compound, named serratamolide G (see Figure 4).

\section{Antimicrobial activities}

The results demonstrate that there was no inhibition zone for Staphylococcus aureus, Escherichia coli, Bacillus subtilis. There were antibacterial circles of Candida albicans and Bacillus thuringiensis. Table 2 showed the size of the inhibition zone was $22 \pm 0.2 \mathrm{~mm}$ against C. albicans and $12 \pm 0.1 \mathrm{~mm}$ against $B$. thuringiensis for Compound 1 (prodigiosine). It was $20 \pm 0.2 \mathrm{~mm}$ against $C$. albicans and $14 \pm 0.3 \mathrm{~mm}$ against $B$. thuringiensis for Compound 3 (serratamolide G) at $200 \mu \mathrm{g}$ $\mathrm{ml}^{-1}$. Moreover, compared to a standard antibiotic (penicillin), prodigiosine and serratamolide $G$ showed similar intensities of antibacterial activity. C. albicans is more sensitive to prodigiosine and serratamolide $\mathrm{G}$ compared with B. thuringiensis (Figure 5). 
Page 6 of 7

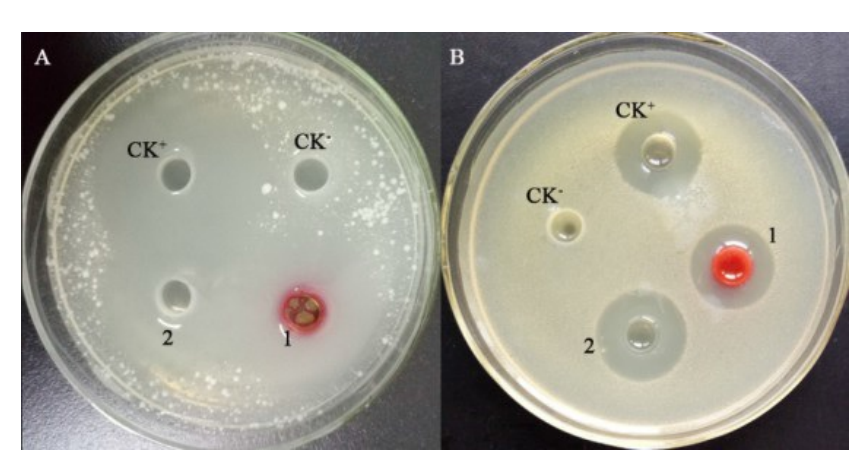

Figure 5: Inhibition effect of pathogenic bacterium. A, Inhibition zone of Bacillus thuringiensis; $\mathrm{B}$, Inhibition zone of Bacillus thuringiensis; 1 , Prodigiosine; 2, Serratamolide G; $\mathrm{CK}^{+}$, Penicillin, as the positive control; $\mathrm{CK}^{-}$, Methanol, as the negative control.

\begin{tabular}{|l|l|l|}
\hline Samples & Candida albicans & Bacillus thuringiensis \\
\hline Prodigiosine & $22 \pm 0.2 \mathrm{~mm}$ & $12 \pm 0.1 \mathrm{~mm}$ \\
\hline Serratamolide A & $20 \pm 0.2 \mathrm{~mm}$ & $14 \pm 0.3 \mathrm{~mm}$ \\
\hline
\end{tabular}

\begin{tabular}{|l|l|l|}
\hline Penicillin & $22 \pm 0.3 \mathrm{~mm}$ & $13 \pm 0.2 \mathrm{~mm}$ \\
\hline Methanol & $8 \pm 0.1 \mathrm{~mm}$ & $8 \pm 0.2 \mathrm{~mm}$ \\
\hline
\end{tabular}

Table 2: Inhibition effect of pathogenic bacterium.

The results of the agar diffusion assay and the microdilution method displays the MIC of prodigiosin and serratamolide $\mathrm{G}$ for $C$. albicans $\left(6.25 \mu \mathrm{g} . \mathrm{mL}^{-1}\right.$ and $\left.6.25 \mu \mathrm{g} \cdot \mathrm{mL}^{-1}\right)$ and $B$. thuringiensis $\left(25 \mu \mathrm{g} . \mathrm{mL}^{-1}\right.$ and $25 \mu \mathrm{g} \cdot \mathrm{mL}^{-1}$ ) and $\mathrm{MBC}$ of prodigiosin and serratamolide $\mathrm{G}$ for $C$. albicans $\left(12.5 \mu \mathrm{g} . \mathrm{mL}^{-1}\right.$ and $\left.12.5 \mu \mathrm{g} . \mathrm{mL}^{-1}\right)$ and B. thuringiensis $(25$ $\mu \mathrm{g} . \mathrm{mL}^{-1}$ and $\left.25 \mu \mathrm{g} . \mathrm{mL}^{-1}\right)$ respectively.

\section{The inhibitory activity of bacterial extracts on plant pathogenic bacteria}

The inhibitory effects of extracts of Serratia marcescans $\$ 823$ against 4 types of pathogenic fungi, Fusarium oxysporum f. sp. niveum, Verticillium dahliae Kleb, Botryosphaeria dothidea and Fusarium oxysporum f. sp. Vasinfectum, were determined by the growth rate method. Table 3 shown that the extracts of Serratia marcescans S823 had an inhibitory effect on the four plant pathogenic fungi.

\begin{tabular}{|l|l|l|}
\hline $\begin{array}{l}\text { The plant pathogenic } \\
\text { fungi }\end{array}$ & Methanol Diameter $(\mathbf{m m})$ & Extract of S823 Diameter $(\mathbf{m m})$ \\
\hline $\begin{array}{l}\text { Fusarium oxysporum } f . \\
\text { sp. vasinfectum }\end{array}$ & $75.60 \pm 0.39$ & $17.30 \pm 0.36$ \\
\hline Botryosphaeria dothidea & $90.00 \pm 0.58$ & $23.19 \pm 0.50$ \\
\hline $\begin{array}{l}\text { Fusarium oxysporum f. } \\
\text { sp. niveum }\end{array}$ & $70.10 \pm 2.10$ & $26.00 \pm 1.95$ \\
\hline $\begin{array}{l}\text { Verticillium dahliae } \\
\text { Kleb }\end{array}$ & $64.70 \pm 2.75$ & $25.31 \pm 0.53$ \\
\hline
\end{tabular}

Table 3: Inhibition effect of pathogenic fungus.

\section{Discussion}

Antibiotic treatment failure and a search for new active components from microorganisms motivated this study. We investigated compounds from Serratia marcescans and isolated prodigiosine (PG) and serratamolide $\mathrm{G}$ by bioactivity-guided analysis. These compounds showed strong antibacterial activities against Candida albicans and Bacillus thuringiensis. Prodigiosine is a tripyrrolic, red-pigmented alkaloid produced by Gram-positive bacteria and Gram-negative bacteria, such as Pseudomonas, Vibrio, Streptomyces and Serratia [2]. It was found to have a broad spectrum of activity against a wide range of Gram-positive and Gram-negative bacteria [5]. This natural product has attracted widespread attention in the medicinal chemistry field because of its wide range of biological activities, including antimicrobial activity [5], anti-malaria activity [6,7], immunosuppressive activity $[4,9,10]$, and antitumor activity [11-13]. Here, it was completely synthesized [4]. Prodigiosine and serratamolide $G$ had almost the same strong antibacterial activities against Candida albicans as penicillin, the standard antibiotic for treatment. Candida albicans infections are the major source of fungal infections in critically ill or otherwise immunocompromised patients [20]. Treatments for Candida infection commonly include amphotericin B [21], echinocandin, or fluconazole for systemic infections, nystatin for oral and oesophageal infections, clotrimazole for skin and genital yeast infections. That serratamolide $G$ has antifungal activities were reported.

\section{Conclusion}

This study highlights the antimicrobial activity of natural products, such as prodigiosine and serratamolide $\mathrm{G}$. This suggests that the active natural products might be potential alternative treatment options for Candida albicans infection.

\section{Acknowledgement}

This study was supported by the National Natural Science Foundation of China, performed under Project No. 21366012. 


\section{References}

1. Boonlarppradab C, Kauffman CA, Jensen PR, Fenical W (2008) Marineosins $\mathrm{A}$ and $\mathrm{B}$, cytotoxic spiroaminals from a marine-derived actinomycete. Org Lett 10: 5505-5508.

2. Hu DX, Withall DM, Challis GL, Thomson RJ (2016) Structure, chemical synthesis, and biosynthesis of prodiginine natural products. Chem Rev 116: 7818-7853.

3. Nisha KK, Kumar V (2013) Prodigiosin alkaloids: recent advancements in total synthesis and their biological potential. RSC Adv 5: 10899-10920.

4. Li J, Zhang Q, Yin J, Yu CJ (2016) Metal-free and versatile synthetic routes to natural and synthetic prodiginines from boron dipyrrin. Org Lett 18: 5696-5699.

5. Marchal E, Uddin MI, Smithen DA, Hawco CLA (2013) Antimicrobial activity of non-natural prodigiosenes. RSC Adv 3: 22967-22971.

6. Kancharla P, Lu W, Salem SM, Kelly JX (2014) Stereospecific synthesis of 23-hydroxyundecylprodiginines and analogues and conversion to antimalarial premarineosins via a rieske oxygenase catalyzed bicyclization. J Org Chem 79: 11674-11689.

7. Kancharla P, Kelly JX, Reynolds KA (2015) Synthesis and structure -activity relationships of tambjamines and B-ring functionalized prodiginines as potent antimalarials. J Med Chem 58: 7286-7309.

8. Lee MH, Kataoka T, Honjo N, Magae J (2009) In vivo rapid reduction of alloantigen-activated CD8+ mature cytotoxic $\mathrm{T}$ cells by inhibitors of acidification of intracellular organelles, prodigiosin 25-C. Immunol 99: 243-248.

9. Azuma T, Watanabe N, Kobayashi Y (2000) Induction of apoptosis of activated murine splenic $\mathrm{T}$ cells by cycloprodigiosin hydrochloride a novel Immunosuppressant. Immunopharmacol 46: 29-37.

10. Stepkowski SM, Erwin-Cohen RA, Kirken RA (2002) Selective inhibitor of Janus tyrosine kinase 3, PNU156804, prolongs allogra t survival and acts synergistically with cyclosporine but additively with rapamycin. Blood 99: 680-689.
11. Smithen DA, Forrester AM, Corkery DP, Dellaire G, Colpitts J (2013) Investigations regarding the utility of prodigiosenes to treat leukemia. Org Biomol Chem 11: 62-68.

12. Hawco CLA, Marchal E, Uddin MI, Baker AEG (2013) Synthesis and biological evaluation of prodigiosene conjugates of porphyrin, estrone and 4-hydroxytamoxifen. Bioorg Med Chem 21: 5995-6002.

13. Marchal E, Rastogi S, Thompson A, Davis JT (2014) Influence of B-ring modifications on proton affinity, transmembrane anion transport and anti-cancer properties of synthetic prodigiosenes. Org Biomol Chem 12: 7515-7522.

14. Wasserman H, Keggi J, McKeon J (1961) Serratamolide, A metabolic product of Serratia. J Am Chem Soc 83: 4107-4118.

15. Wasserman H, Keggi J, McKeon J (1962) The Structure of Serratamolide1-3. J Am Chem Soc 84: 2978-2982.

16. Pang CP, Cao YT, Zhu XD (2016) Biotransformation of cholesterol and 16,17-alpha epoxypregnenolone by novel Cladosporium sp. strain IS547. J Basic Microbiol 56: 1-9.

17. Farzaneh A, Ju KS, Jozsef L, Bruc DH (2008) Antibacterial colorants: characterization of prodiginines and their applications on textile materials. Biotechnol Prog 24: 742-747.

18. Margaret ACB, Deol BS, Stil JL (1970) The occurrence of bound serine in acetone extracts of Serratia marcescens exclusively in compounds of a cyclic depsipeptide structure related to serratamolide. Biochem J 116: 759-761.

19. Deepti D, Rolf J, Gabriella M, Manfred N (2008) Antimycobacterial serratamolides and diacyl peptoglucosamine derivatives from serratia sp. J Nat Prod 71: 637-641.

20. Emily RMS, Trish MP (2011) Hospital Epidemiology and Infection Control in Acute-Care Settings. Clin Microbiol Rev 24: 141-173.

21. Rambach G, Oberhauser H, Speth C, Lass-Flörl C (2011) Susceptibility of Candida species and various moulds to antimycotic drugs: Use of epidemiological cutoff values according to EUCAST and CLSI in an 8year survey. Med Mycol 49: 856-863. 